\title{
Synthesis and X-Ray Diffraction Analyses of Calcium Hydroxide Nanoparticles in Aqueous Suspension
}

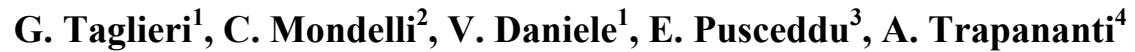 \\ ${ }^{1}$ University of L'Aquila, Department of Industrial and Information Engineering and Economics, L'Aquila, Italy \\ ${ }^{2}$ CNR-IOM-OGG Institut Laue Langevin, Grenoble, France \\ ${ }^{3}$ Institut Laue Langevin, Grenoble, France \\ ${ }^{4}$ CNR-IOM-OGG, c/o ESRF, Grenoble, France \\ Email: giuliana.taglieri@univaq.it, valeria.daniele@univaq.it, mondelli@ill.fr, angela.trapananti@esrf.fr
}

Received January 24, 2013; revised March 12, 2013; accepted April 17, 2013

Copyright (C) 2013 G. Taglieri et al. This is an open access article distributed under the Creative Commons Attribution License, which permits unrestricted use, distribution, and reproduction in any medium, provided the original work is properly cited.

\begin{abstract}
Calcium hydroxide nanoparticles in aqueous suspensions (also called nanolime) were successfully employed in Cultural Heritage conservation thanks to the ability of favoring re-adhesion of the pictorial layer on original carbonatic substrates or allowing to a better superficial cohesion and protection of treated stones. In this work, we have synthesized nanolime particles in aqueous suspension by two different methods. The produced particles were characterized in the laboratory, in terms of structural and morphological features, by means of X-Ray diffraction powder (XRD) and by transmission electron microscopy (TEM), respectively. Nanoparticles were crystalline, regularly shaped, hexagonally plated and with side dimensions generally ranging from $300 \mathrm{~nm}$ to $30 \mathrm{~nm}$ or less. Crystal structure of nanolime particles directly in the aqueous suspension, has been also analyzed by synchrotron diffraction from X-ray synchrotron radiation (SR-XRD); data have been analyzed by means of the Rietveld method and we have investigated the structure of $\mathrm{Ca}(\mathrm{OH})_{2}$ particles in suspension in terms of cell parameters, atomic coordinates, bond lengths and angles.
\end{abstract}

Keywords: Nanoparticles; Calcium Hydroxide; Crystal Structure; X-Ray Diffraction; Crystal Morphology

\section{Introduction}

Calcium hydroxide $\left(\mathrm{Ca}(\mathrm{OH})_{2}\right)$, has been largely employed thanks to the well-known carbonation reaction and to the characteristics of the calcium carbonate $\left(\mathrm{CaCO}_{3}\right)$ obtained. The low solubility and the compatibility between the latter compound and material substrates offer a favorable use in many lime-based superficial conservative treatments [1]. In all its applications, a high reactivity is of paramount importance, so that $\mathrm{Ca}(\mathrm{OH})_{2}$ particles with sub micrometric dimensions (nanolime) have been recently successfully employed on Cultural Heritage conservation, offering the possibility to penetrate deep into damaged zones (less limitations due to the particle size), high reactivity and fast reactions (such as carbonatation), high purity and defined composition [2-4 and refs. therein]. Nanolime is typically synthesized by a chemical precipitation process in supersaturated aqueous solutions of reactants; in particular, the method starts from aqueous sodium hydroxide solution $(\mathrm{NaOH})$ added drop by drop in an aqueous calcium chloride $\left(\mathrm{CaCl}_{2}\right)$ solution, maintained at high temperature [5 and refs. therein].

The synthesis allows to obtain $\mathrm{Ca}(\mathrm{OH})_{2}$ nanoparticles directly in suspension, as they are used in the applications. It is fundamental to verify that the obtained nanoparticles, very reactive thanks to their dimensions, don't show the carbonatation process inside the suspension, but only during the applicative use, when the solvent is completely evaporated.

The aim of this work has been to synthesize $\mathrm{Ca}(\mathrm{OH})_{2}$ nanoparticles by different methods and to compare the obtained results, in terms of structural features of the particles both in the aqueous suspension and after the solvent was completely evaporated. In particular, two nanolime synthesis methods, reported in our previous works $[2,6]$, have been followed. According to method (A), synthesis has been carried out by adding (drop by drop) an aqueous $\mathrm{NaOH}$ solution into a $\mathrm{CaCl}_{2}$ one, maintained at $90^{\circ} \mathrm{C}$. According to method (B), a surfactant agent (Triton X-100) was previously added to the two initial aqueous solutions that were later mixed $s i$ multaneously, at the fixed temperature of $90^{\circ} \mathrm{C}$. The method (B) allows to obtain $\mathrm{Ca}(\mathrm{OH})_{2}$ nanoparticles easily and drastically reducing the time of synthesis. In fact, especially if tenths of grams were prepared, we passed 
from several hours for the drop by drop method to few minutes; this difference in time scales with the quantity of the preparation, allowing us to scale-up the nanolime production only when the method (B) is followed.

The morphology and particles size have been investigated by transmission electron microscopy (TEM).

We have investigated the phases formed after the synthesis procedure, by means of X-ray diffraction powder technique (XRD). The XRD diffraction is a powerful, non-destructive and useful technique that allow to quickly analyze unknown materials, in terms of crystallinity and phases identification, and to perform materials characterization in many scientific fields such as engineering, metallurgy, mineralogy, sciences, archeology, etc. The great advantages of this technique are: the simplicity in sample preparation, the rapidity of measurement, the ability to analyze mixed phases, the structure determination directly in laboratory. In particular, XRD technique can easily allow to investigate the reactivity, in terms of carbonatation process efficiency, of the produced calcium hydroxide nanoparticles. For this reason, we have considered different agglomeration conditions of the nanoparticles (that could strongly influence the carbonatation process) partially substituting water with 2-propanol, as disagglomerating agent [2]. In particular, for each method, four nanolime suspensions were prepared, characterized by different residual water contents in the precipitated phase.

We have also investigated the $\mathrm{Ca}(\mathrm{OH})_{2}$ nanoparticles crystalline structure directly in aqueous suspension by using synchrotron radiation at the European Synchrotron Radiation Facility (ESRF)-Grenoble, France. In fact, the high energy and high flux of this source allowed diffraction measurements in transmission of the particles inside the aqueous medium. X-ray synchrotron diffraction data have been analyzed by means of the Rietveld method and we have investigated the structure of $\mathrm{Ca}(\mathrm{OH})_{2}$ particles in suspension in terms of cell parameters, atomic coordinates, bond lengths and angles.

\section{Experimental Details}

\subsection{Synthesis of $\mathrm{Ca}(\mathrm{OH})_{2}$ Nanoparticles}

Calcium chloride dihydrate $\left(\mathrm{CaCl}_{2} \cdot 2 \mathrm{H}_{2} \mathrm{O}\right)$, sodium hydroxide $(\mathrm{NaOH})$ and 2-propanol pro analysi products, supplied by Merck, have been used without further purification. In case of method B) polyoxyethylene (10) tertoctylphenyl ether, Triton X-100 $\left(\mathrm{C}_{14} \mathrm{H}_{22} \mathrm{O}\left(\mathrm{C}_{2} \mathrm{H}_{4} \mathrm{O}\right)_{10}\right)$, a high-purity, water-soluble, liquid, non-ionic surfactant, purchased from Fluka has been used too. Water has been purified by a Millipore Organex system $(\mathrm{R} \geq 18 \mathrm{M} \Omega$ $\mathrm{cm})$.

Method (A). We have prepared two different aqueous solutions of $100 \mathrm{ml}$, containing $0.3 \mathrm{~mol} / 1$ of $\mathrm{CaCl}_{2} \cdot 2 \mathrm{H}_{2} \mathrm{O}$ and $0.6 \mathrm{~mol} / \mathrm{l}$ of $\mathrm{NaOH}$ respectively. The $\mathrm{NaOH}$ alkaline solution (used as precipitator) has been added drop by drop into the $\mathrm{CaCl}_{2}$ solution (speed $\approx 4 \mathrm{ml} / \mathrm{min}$, temperature of $90^{\circ} \mathrm{C}$ ). After about 24 hours two distinct phases have been observed, a limpid supernatant solution and a white precipitated phase; to remove the $\mathrm{NaCl}$ produced, several deionised water washings have been performed. Aqueous nanolime suspension (with a $\mathrm{Ca}(\mathrm{OH})_{2}$ concentration of $10 \mathrm{mg} / \mathrm{ml}$ ) has been defined as sample A.

Method (B). ( $4.00 \pm 0.02) \mathrm{g}$ of Triton X-100 has been previously added to the initial aqueous solutions containing $0.3 \mathrm{~mol} / 1$ of $\mathrm{CaCl}_{2} \cdot 2 \mathrm{H}_{2} \mathrm{O}$ and $0.6 \mathrm{~mol} / \mathrm{l}$ of $\mathrm{NaOH}$ respectively (each solution was $100 \mathrm{ml}$ in volume). These initial solutions have been then mixed together simultaneously, at the temperature of $90^{\circ} \mathrm{C}$. A suspension of $200 \mathrm{ml}$ of final volume has been obtained, characterized by a $\mathrm{Ca}(\mathrm{OH})_{2}$ concentration of $10 \mathrm{mg} / \mathrm{ml}$ (sample B). As in method (A), we have performed several deionised water washings to remove the $\mathrm{NaCl}$ produced and the surfactant too.

For both the methods, different residual water contents were considered preparing four samples, named $A_{100}, A_{75}$, $\mathrm{A}_{50}, \mathrm{~A}_{25}, \mathrm{~B}_{100}, \mathrm{~B}_{75}, \mathrm{~B}_{50}, \mathrm{~B}_{25}$, respectively: the subscript represents the percentage of water content in each sample.

\subsection{Characterization of $\mathrm{Ca}(\mathrm{OH})_{2}$ Nanoparticles}

By TEM technique (Philips CM 100), the dried particles morphology of the samples under study have been analyzed; measurements have been performed on the samples dried under vacuum, following the common procedure.

As concerns XRD measurements (Philips X' Pert PW 1830 ), performed in our laboratory to determine the crystalline degree and the phases of the formed particles, the sample was prepared maintaining each aqueous suspension for 20' in ultrasonic bath (US) and then depositing $0.2 \mathrm{ml}$ of the suspension itself on a silica sample holder; measures were performed on dry sample, in laboratory conditions $\left(\mathrm{T}=20^{\circ} \mathrm{C}\right.$, relative humidity $\mathrm{RH}=$ $40 \%$ ). Each experimental diffraction spectrum has been elaborated by a Profile Fit Software (Philips PROFIT $v .1 .0)$ and each crystalline phase has been attributed by JCPDS patterns; the ratio between the calcium carbonate peaks area and the spectrum total area has been assumed as the carbonatation process efficiency (yield).

Crystal structure of the nanolime particles directly in aqueous suspension has been investigated by SR-X ray measurements on GILDA (BM08) beamline at ESRF; the patterns were collected in Debye-Scherrer geometry on a 2D image plate detector. The experiment was performed at an incident beam wavelength of $\lambda=0.7277 \AA$ and the sample-to-detector distance adjusted to obtain data within the $6^{\circ}-53^{\circ} 2 \theta$-angle range. Data were collected from 0.2 
$\mathrm{ml}$ of aqueous suspension sealed within a cell with Kapton windows, mounted on a rotating sample holder in order to avoid deposition of the nanoparticles during the measurement, to make a good average of the structural characteristics of the particles in suspension and to improve statistics. Patterns of water alone and Triton X-100 have been also collected to consider their contribution to the background in aqueous $\mathrm{Ca}(\mathrm{OH})_{2}$ suspensions spectra. Data have been collected on a 2D image plate and integrated, after standard calibration and corrections, to obtain $\mathrm{I}(2 \theta)$ data, then analyzed by Rietveld method (FullProf package [7]). $\mathrm{Ca}(\mathrm{OH})_{2}$ structural refinements have been performed considering the P-3 $\mathrm{ml}$ space group, taking ICSD data as initial values [8]. We have refined zero point, scale factor, cell parameters, bond lengths and angles, Debye Waller factors and preferred orientation parameters. By Rietveld analysis we have also determined the coherent domain size for each considered sample. In particular, the average apparent size has been calculated using the different reciprocal lattice vectors as reported in Fullprof manual [7].

\section{Results and Discussion}

From TEM measurements, here we have reported some images taken as representative micrographs for each sample analyzed.

In particular, in Figure 1(a) TEM images on sample A, showed as the particles appear hexagonally plated and regularly shaped with side dimension up to $400 \mathrm{~nm}$, as reported in our previous work [4]. As concerns sample B (Figure 1(b)), characterized by the presence of a surfactant content that could be not completely removed by washings, we have observed that some particles have the side dimension of about 100 - $150 \mathrm{~nm}$; moreover, many particles with diameter less than $20 \mathrm{~nm}$ have been observed too.

The results obtained by TEM images, could be explained considering that the surfactant can affect the nanolime formation. It could be supposed that, during the growth of the nanolime crystals, the molecular units of the surfactant stick on the surface of the crystals by weak forces; they gradually could form a film that prevents the growth of the formed crystals.

XRD spectra, in relation to the different water content in the nanolime suspension, have been reported in Figure 2 while in Table 1 we have reported the results of the estimated yield values $\left(\mathrm{T}=20^{\circ} \mathrm{C}, \mathrm{RH}=40 \%\right)$.

From Table 1, we have observed that water play an important role in the carbonatation process; in fact, samples characterized by water percentage $\leq 50 \%$ show the lowest yield values. Moreover, as concerns the sample without the surfactant (sample A), 2-propanol seems to improve disagglomeration of the particles, and so a higher specific surface, so favoring the carbonatation up to

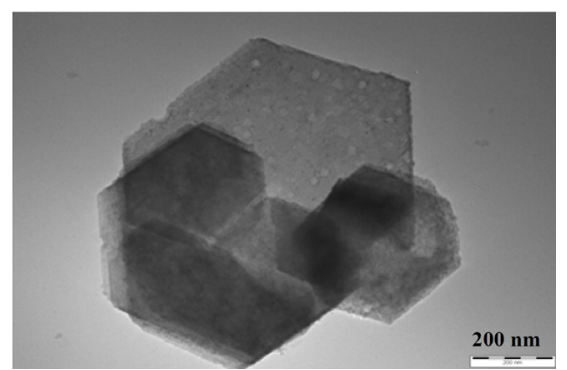

(a)

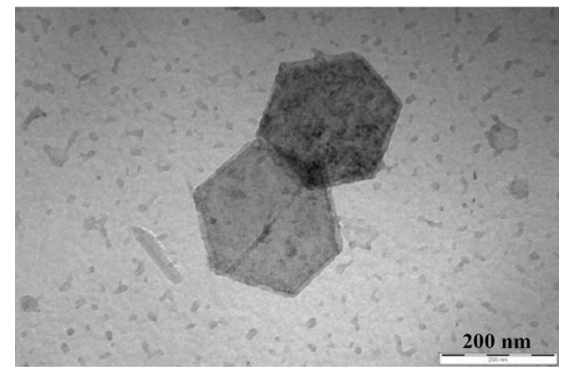

(b)

Figure 1. TEM micrographs on: (a) sample $\mathrm{A}-\mathrm{Ca}(\mathrm{OH})_{2}$ particles, hexagonally plated and regularly shaped, with side dimension up to $400 \mathrm{~nm}[4]$; (b) sample B-many particles with dimension $<20 \mathrm{~nm}$ were observed together with few particles of side dimension up to150 $\mathrm{nm}$.

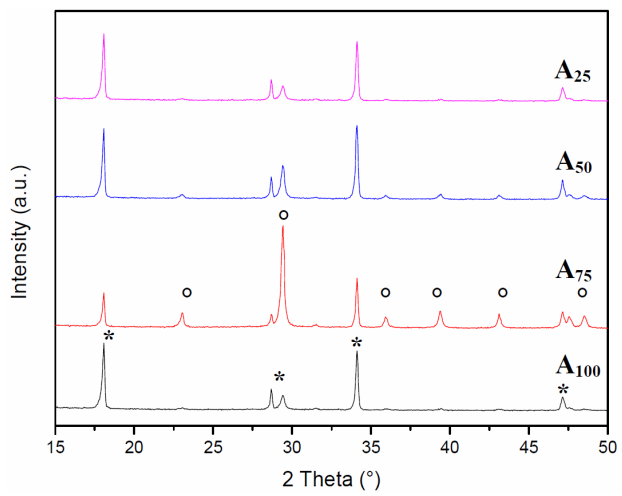

(a)

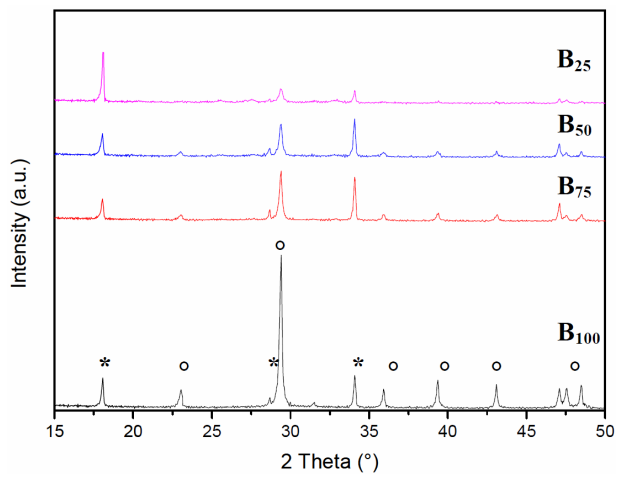

(b)

Figure 2. XRD patterns of the aqueous nanolime suspensions after 30 minutes of air exposition time: (a) sample $A$; (b) sample B. Legend: ${ }^{*} \mathrm{Ca}(\mathrm{OH})_{2} ;{ }^{\circ} \mathrm{CaCO}_{3}$ 
Table 1. Yield values estimated by XRD measurements in relation to different residual water content of nanolime suspensions synthesized without or with the surfactant agent (samples A and B, respectively).

\begin{tabular}{|c|c|c|c|c|}
\hline Nanolime suspension & Sample & Residual water content $(\%)$ & 2-propanol (\%) & Yield (\%) \\
\hline \multirow{4}{*}{$\mathbf{A}$} & $\mathrm{A}_{100}$ & 100 & - & 50 \\
\hline & $\mathrm{A}_{75}$ & 75 & 25 & 80 \\
\hline & $\mathrm{A}_{50}$ & 50 & 50 & 33 \\
\hline & $\mathrm{A}_{25}$ & 25 & 75 & 15 \\
\hline \multirow{4}{*}{ B } & $\mathrm{B}_{100}$ & 100 & - & 80 \\
\hline & $\mathrm{B}_{75}$ & 75 & 25 & 60 \\
\hline & $\mathrm{B}_{50}$ & 50 & 50 & 50 \\
\hline & $\mathrm{B}_{25}$ & 25 & 75 & 30 \\
\hline
\end{tabular}

80\% (sample $\mathbf{A}_{\mathbf{7 5}}$ ).

On the contrary, in sample $\mathbf{B}$ (where the surfactant is present), all the carbonatation yield values were probably higher due to the particles decreasing, as confirmed by TEM investigation (Figure 1). Nevertheless, this tendency was not observed in sample $\mathbf{B}_{75}$, as if the alcohol ability to disagglomerate the nanoparticles was reduced by the presence of the surfactant.

Analysis of the SR-XRD data allows us to determine that the $\mathrm{Ca}(\mathrm{OH})_{2}$ nanoparticles don't show the carbonatation process inside the suspension. Besides, we have determined the structural parameters of the $\mathrm{Ca}(\mathrm{OH})_{2}$ crystals in aqueous suspensions synthesized by the two different methods, in terms of cell parameters, atomic coordinates, interatomic distances and bond angles, DebyeWaller factors, preferred orientation of crystallites and average grain dimension. We have used the pseudo-Voigt profile function of Thompson, Cox and Hastings [9] in order to fit the peak shapes. The instrumental contribution to peak broadening was determined measuring a diffraction pattern of a LaB6 sample in the same geometry of the samples [10].

SR-X ray diffraction patterns for samples $\mathbf{A}$ and $\mathbf{B}$, refined with Rietveld method, have been reported in Figure 3 as an example of the quality of the refinement that can be appreciated from the spectra-difference (in blue) between the measured spectra (in red) and the calculated spectra (in black); the green lines indicate the Bragg reflections. The most intense peaks have been indexed and we observed that only the $\mathrm{Ca}(\mathrm{OH})_{2}$ crystalline phase is stably present in suspension, with the main Bragg reflection attributed to $(101)$ peak $\left(\mathrm{d}_{101}=1.33 \AA\right)$ and it can be described in the space group P-3 ml.

In Table 2, structural results have been reported, considering the comparison between samples $\mathbf{A}$ and $\mathbf{B}$, respectively. In particular, cell volumes in sample $\mathbf{B}$ ap-peared smaller respect to those relative to sample $\mathbf{A}$; this result can be explained considering that the addition of surfactant tends to favor, in aqueous suspension, smaller calcium hydroxide cell volume. As concerns $\mathrm{Ca}-\mathrm{O}$ and $\mathrm{O}-\mathrm{H}$ distances and bond angles, they were not influenced

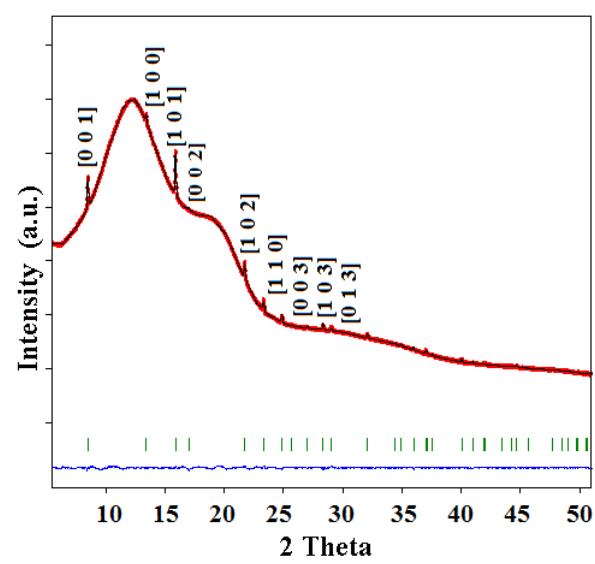

(a)

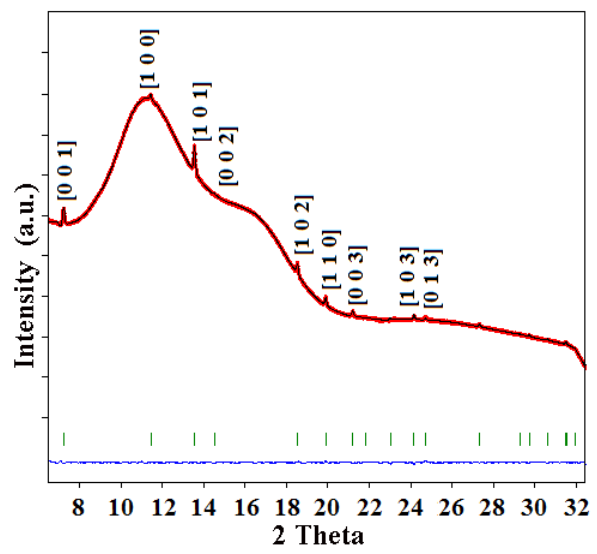

(b)

Figure 3. SR-X ray diffraction patterns refined with Rietveld method; (a) sample A; (b) sample B. The difference between the measured spectra (red line) and the calculated ones (black line) is reported in blue line; the green lines indicate Bragg reflection.

by the synthesis method.

Finally, by Rietveld analysis [7] we have also determined the average apparent size for each considered sample. Calculating, for each reflection, the coherent domain size, we have found average values of 147.6 (1) nm (sample A) and 92.94 (4) nm (sample B), showing sub 
Table 2. Cell parameters and volume, interatomic distances and bond angles of $\mathrm{Ca}(\mathrm{OH})_{2}$ particles in aqueous suspendsion, synthesized without and with the addition of the surfactant.

\begin{tabular}{ccc}
\hline & Sample A & Sample B \\
\hline $\mathrm{a}(\AA)$ & $3.599(1)$ & $3.588(1)$ \\
$\mathrm{b}(\AA)$ & $3.599(1)$ & $3.588(1)$ \\
$\mathrm{c}(\AA)$ & $4.917(3)$ & $4.906(3)$ \\
Volume & $55.16(4)$ & $54.69(4)$ \\
Ca-O distance $(\AA)$ & $2.5(1)$ & $2.43(8)$ \\
O-H distance $(\AA)$ & $1.9(3)$ & $1.9(2)$ \\
O-Ca-O angle $\left({ }^{\circ}\right)$ & $94(4)$ & $95(3)$ \\
H-Ô-H angle $\left({ }^{\circ}\right)$ & $33(1)$ & $37(9)$ \\
\hline
\end{tabular}

microcrystalline phases, in particular for the sample synthesized by the addition of surfactant.

\section{Conclusions}

The present work was focused on a new synthesis of $\mathrm{Ca}(\mathrm{OH})_{2}$ nanoparticles, in aqueous suspensions, by adding a surfactant agent in the initial reactants, so obtaining very small particles easily and reducing drastically the time needful for preparation. We have studied $\mathrm{Ca}(\mathrm{OH})_{2}$ nanoparticles, synthesized in our laboratory, in terms of structural and morphological features, by means of XRay diffraction powder (XRD) and by transmission electron microscopy (TEM). The $\mathrm{Ca}(\mathrm{OH})_{2}$ nanoparticles, studied also in terms of the carbonatation process by $\mathrm{XRD}$, appeared crystalline, hexagonally plated and regularly shaped, with dimensions ranging from $300 \mathrm{~nm}$ to 30 $\mathrm{nm}$ or less.

By means of synchrotron radiation (SR-XRD) we have studied the structure of the $\mathrm{Ca}(\mathrm{OH})_{2}$ nanoparticles directly in aqueous suspension. From Rietveld refinement of SR-X ray diffraction data, we have found that the addition of surfactant during the synthesis tends to reduce the cell volumes of $\mathrm{Ca}(\mathrm{OH})_{2}$ particles in aqueous suspension.

\section{REFERENCES}

[1] E. Doehne and C. A. Price, "Stone Conservation. An Overview of Current Research," 2nd Edition, Getty Conserva- tion Institute, Getty Publications, Los Angeles, 2010, pp. 35-37.

[2] V. Daniele and G. Taglieri, "Nanolime Suspensions Applied on Natural Lithotypes: The Influence of Concentration and Residual Water Content on Carbonatation Process and on Treatment Effectiveness," Journal of Cultural Heritage, Vo. 11, No. 1, 2010, pp. 102-106. doi:10.1016/j.culher.2009.04.001

[3] L. Dei and B. Salvadori, "Nanotechnology in Cultural Heritage Conservation: Nanometric Slaked Lime Saves Architectonic and Artistic Surfaces from Decay," Journal of Cultural Heritage, Vol. 7, No. 2, 2006, pp. 110-115. doi:10.1016/j.culher.2006.02.001

[4] V. Daniele and G. Taglieri, " $\mathrm{Ca}(\mathrm{OH})_{2}$ Nanoparticle Characterization: Microscopic Investigation of Their Application on Natural Stones," In: A. A. Mammoli, C. A. Brebbia and A. Klemm, Eds., Materials Characterisation V, WIT Press, Southampton, 2011, pp. 55-66.

[5] V. Daniele, G. Taglieri and R. Quaresima, "The Nanolimes in Cultural Heritage Conservation: Characterisation and Analysis of the Carbonatation Process," Journal of Cultural Heritage, Vol. 9, No. 3, 2008, pp. 294-301. doi:10.1016/j.culher.2007.10.007

[6] V. Daniele and G. Taglieri, "Synthesis of $\mathrm{Ca}(\mathrm{OH})_{2}$ Nanoparticles with the Addition of Triton X-100. Protective Treatments on Natural Stones: Preliminary Results," Journal of Cultural Heritage, Vol. 13, No. 1, 2012, pp. 40-46. doi:10.1016/j.culher.2011.05.007

[7] J. Rodriguez-Carvajal, "Fullprof Program," Physica B, Vol. 192, No. 1-2, 1993, pp. 55-69.

[8] L. Desgranges, et al., "Hydrogen Thermal Motion in Calcium Hydroxide: $\mathrm{Ca}(\mathrm{OH})_{2}, "$ Acta Crystallographica B, Vol. 49, 1993, pp. 812-817.

[9] P. Thompson, D. E. Cox and J. B. Hastings, "Rietveld Refinement of Debye-Scherrer Synchrotron X-Ray Data from $\mathrm{Al}_{2} \mathrm{O}_{3}$," Journal of Applied Crystallography, Vol. 20, 1987, pp. 79-83.

[10] S. Rasberry, et al., "National Institute of Standards and Technology SRM Certificates, Standard Reference Materials 660. Report," National Institute of Standards and Technology, Gaithersburg, 1989. 